\title{
PEMAMPAATAN LIMBAH KERTAS MENJADI KALIGRAFI HIASAN DINDING KAMPUNG JALIN KOTA JANTHO
}

\author{
Anni Kholilah ${ }^{1}$, Hatmi Negria Taruan², Reza Sastra $W^{3}$ \\ Institut Seni Budaya Indonesia Aceh \\ e-mail : anni.kholilah43@gmail.com, hatmi.negria87@gmail.com, reyzasastra@gmail.com
}

Diterima : 1 Maret 2019. Disetujui : 9 Mei 2019. Dipublikasikan : 30 Juni 2019

(C)2019 - DESKOVI Universitas Maarif Hasyim Latif. Ini adalah artikel dengan akses terbuka di bawah lisensi CC BY 4.0 (https://creativecommons.org/licenses/by/4.0/)

\begin{abstract}
ABSTRAK
Kampung jalin merupakan daerah yang berdekatan dengan kota Jantho. Jarak jalin dengan kota jantho dapat diakses dengan kendaraan roda empat maupun roda dua selama \pm 30 menit perjalanan. Secara geografis jalin dikelilingi lahan subur sehingga sebagian besar masyarakat jalin kondisi tersebut mengindikasikan bahwa jalin didominasi oleh sektor pertanian dan perkebunan, sedangkan potensi kesenian masih sangat minim terutama di bidang seni rupa. hal tersebut menimbulkan pemikiran bahwa peluang seni rupa untuk berkembang masih sangat terbuka. Minimnya pengetahuan masyarakat akan keterampilan seni membutuhkan bimbingan dan pelatihan oleh tenaga ahli sehingga keterampilan seni ini sendiri dapat di konversi menjadi peluang usaha dan memiliki nilai ekonomis, salah satunya dengan memanfaatkan limbah kertas menjadi kaligrafi hias sebagai cendra mata. Kaligrafi hias merupakan cara sederhana mengolah bahan-bahan kertas tidak terpakai menjadi hiasan dengan memanfaatkan benda-benda sederhana yang diolah sedemikian rupa sehingga menjadi benda yang memiliki nilai seni dan memiliki nilai jual. Keutamaan kaligrafi hias ini sendiri yakni dari bahan-bahan baku yang mudah didapatkan dengan harga yang tergolong cukup murah dan memiliki nilai jual yang tinggi.
\end{abstract}

Kata kunci: Kaligrafi hias, Limbah kertas, Pengabdian masyarakat

\section{ABSTRACT}

Interlace village is an area adjacent to the city of Jantho. Distance intertwined with the city of Jakarta can be accessed by four-wheeled vehicles or two-wheeled vehicles for \pm 30 minutes. Geographically intertwined surrounded by fertile land so that most people intertwine these conditions indicate that interbreeding is dominated by the agricultural and plantation sectors, while the potential of art is still very minimal, especially in the field of art. this raises the idea that the opportunities for art to develop are still very open. The lack of public knowledge of art skills requires guidance and training by experts so that the art skills themselves can be converted into business opportunities and have economic value, one of which is by utilizing paper waste into decorative calligraphy as eye cendra. Decorative calligraphy is a simple way to process unused paper materials into decorations by utilizing simple objects that are processed in such a way that they become objects that have artistic value and have selling points. The virtue of this decorative calligraphy is that it is from raw materials that are easily obtained with prices that are quite cheap and have a high selling value.

Keyword: Decorative calligraphy, Paper waste, Community service

\section{PENDAHULUAN}

Aceh merupakan daerah yang secara geografis terletak di ujung pulau sumatera. Hal ini mengindikasikan bahwa di daerah aceh banyak terdapat pantai-pantai yang menarik untuk dikunjungi. Tidak hanya pantai, wisata di perbukitan di Aceh juga menyenangkan. Seperti di Bukit Jalin, Aceh Besar. Bukit Jalin Sebuah bukit yang menyejukkan pemandangan yang luar biasa dengan aliran sungai yang mengalir di bukit itu. Tidak salah bila kampung jalin itu menjadi pilihan utama kami untuk mengembangkan kesenian keterampilan. Dari Kota Jantho, butuh waktu sekitar 20 menit untuk hingga ke tempat tujuan. Objek wisata di sana memang belum ramai dikunjungi wisatawan. Untuk mandi, tidak dikenakan biaya. Aliran air di sungai mengalir deras tidak mengecewakan. Tapi jangan khawatir, di pinggir sungai sangat ramah untuk bermain anak-anak. Untuk menikmati segarnya mandi di objek wisata tersebut, letak sungai ini memang persis di bawah perbukitan Jalin. Kampung Jalin memang sepi yang mayoritas masyarakatnya adalah bukan asli masyarakat jalin, disana matapencahariannya kebanyakan pertanian dan perkebunan.

Kawasan jalin merupakan kawasan yang memiliki potensi alam menguntungkan bagi masyarakat setempat, sasaran dalam program ini adalah 
perkampungan jalin, Kecamatan Kota Jantho Kabupaten Aceh Besar Provinsi Aceh. Berwisata ke Aceh tidak melulu soal pantai. Pada libur, tidak ada salahnya mencoba menikmati sejuknya air sungai dan perbukitan. Atas alasan inilah kami berinisiatif untuk membentuk program guna menambah aktifitas untuk menghasilkan produk yang dapat memiliki nilai jual dan menambah kreatifitas masyarakat itu sendiri. Melihat sumber daya alam yang belum termanfaatkan secara maksimal menjadi kegelisahan bagi kami untuk mengolah dan memanfaatkanya menjadi nilai tambah bagi masyarakat Jalin. Selain itu, sasaran lain yang ingin dicapai adalah menjadikan Jalin sebagai tempat wisata yang penuh industri kesenian. Pada tahap awal ini media yang digunakan untuk pembuatan kerajinan yang memampaatkan limbah kertas, dikarenakan material kertas merupakan material yang praktis dan masih mudah dijangkau.

Daur ulang kertas adalah pengolahan sampah menjadi produk baru untuk digunakan kembali. Tujuan utama dari daur ulang kertas adalah untuk melestarikan teknologi dan lingkungan . Daur Ulang kertas mempertahankan sumber daya alam yang dinyatakan akan menemukan hasil yang baik dan digunakan sebagai bahan baku untuk memproduksi produk baru. Seperti daur ulang semua jenis, daur ulang kertas juga dilengkapi dengan banyak manfaatnya. Kertas daur ulang juga meluas ke aksesoris seperti kartrid digunakan untuk mencetak pada kertas, kerajinan membuat tas, kaligrafi hiasan dinding, dll.

Produk pemampaatan limbah kertas ini akan diolah semenarik mungkin sehingga dapat diterima oleh pasar lokal dan nasional, target dari pemasaran ini adalah, cendra mata wisatawan ke jalin, kota jantho, hotel, café, dan tempat-tempat lainya. Tujuan adalah menciptakan sebuah kerajinan baru di daerah aceh besar yang berpotensi menciptakan lapangan pekerjaan, menciptakan karakteristik kerajinan di bidang seni rupa yang mengemukakan nilai-nilai keislaman, dan meningkatkan perekonomian dan menjadikan kampung jalin sebagai sasaran tempat wisata kerajinan. Manfaat dari kegiatan ini adalah masyarakat bisa memanfaatkan kertas bekas jadi sebuah karya jual, membuka wawasan mereka menjadi kreatif dibidang seni, dan menjadikan masyarakat lebih tau kertas bekas sangat bermanfaat bagi kehidupan.

Sasaran kegiatan pengabdian ini adalah masyarakat kampung Jalin mulai dari anak-anak sampai dewasa yang masih belum tau tentang seni dan perkembangannya.

Pelaksanaan Pengabdian masyarakat tentunya tidak dapat terlepas dari referensi berupa kegiatankegiatan terkait yang telah dilakukan sebelumnya baik yang telah dilakukan sendiri maupun yang di lakukan oleh orang lain. untuk itu diperlukan beberapa data dengan pokok persoalan yang hampir sama yakni pengolahan limbah kertas menjadi benda-benda terpakai dan benda artistik.

Adapun tinjauan pustaka yang telah dilakukan yakni tinjauan terhadap jurnal yang membahas tentang pengolangan kertas yakni antara lain; "Melakukan Daur Ulang Kertas Bekas Dan Dimanfaatkan Dalam Kehidupan Sehari- Hari" (2017), "Pengolahan Limbah Kertas Menjadi Pulp Sebagai Bahan Pengemas Produk Agroindustri (2011)" "Pengelolaan Sampah Kertas Di Indonesia” (2001). Sumber tersebut memberi inspirasi dan ide bahwasanya kertas tidak hanya digunakan sebagai peralatan tulis dan kantor namun juga dapat dijadikan sebagai medium seni.

\section{METODE PENELITIAN}

\section{Identifikasi Masalah}

Masyarakat kampung Jalin sebagian mayoritasnya tidak memiliki aktifitas lain dengan cara inilah mencoba mengisi kegiatan harian mereka dengan kegiatan yang bermanfaat menghasilkan desain produk yang memiliki nilai jual sehingga dapat membantu untuk meningkatkan prekonomian masyarakat setempat. Kegiatan ini juga ditujukan untuk melatih masyarakat dalam mengolah sumber daya alam yang ada sehingga memiliki nilai jual.

\section{Penyusunan Program.}

1. Persiapan.

Pada tahap awal ini, tim harus menyiapkan semua bahan untuk tahap selanjutnya.

2. Sosialisasi kepada masyarakat.

Sosialisasi tentang produk yang akan dibuat mulai dari pengenalan hasil prodak limbah kertas yang dibuat dengan menggunakan media kertas

3. Pengenalan souvenir-souvenir yang menghasilkan produk yang kita inginkan dan cara pembuatannya.

4. Mengajarkan kepada masyarakat cara mengolah bahan dan membuat produk di kampung Jalin.

5. Pelatihan manejemen organisasi masyarakat.

6. Pada tahap ini tim dan pembimbing memberikan pengetahuan seputar manejemen tentang organisasi masyarakat agar masyarakat mampu mengelolanya dengan benar, dan melanjutkanya menjadai usaha mandiri, bisa mengikuti pameran dan basar seni.

7. Pengawasan keberlanjutan program kepada tim mayarakat desa binaan.

8. Masyarakat mampu menjalankan program ini dan tim hanya memonitoring berjalannya kegiatan ini.

9. Evaluasi terhadap program dan pembuatan laporan akhir.

10. Tahap terakhir ini tim melakukan evaluasi atas program dan kemudian membuat laporan akhir.

\section{PEMBAHASAN}

Kaligrafi merupakan seni rupa islam yang berkembang dari zaman ke zaman. Kaligrafi dalam hal ini adalah penerapan tulisan Al'Quran dalam bentuk tulisan arab yang indah. Sangat banyak bentuk gaya huruf yang digunakan dalam pengaplikasiannya. Gaya atau bentuk tulisan tersebut dalam seni kaligrafi arab disebut dengan istilah "khat". Diantara khat yang sering digunakan yakni khat kufi, khat naskhi, khat farisi, khat 
tsuluts, khat diwani dan khat riq'ah. Khat tersebut pada umumnya hanya diaplikasikan pada tempat-tempat ibadah. mencermati hal tersebut dirasa khat-khat ini juga dapat diaplikasikan ke media-media lebih kreatif lainya.

Sebagian seniman muslim ternama di Indonesia juga menerapkan kaligrafi dalam bentuk lukisan. Lukisan tersebut menampilkan tulisan arab dengan gaya khat mereka masing-masing, seperti Syaiful Adnan dan AD Pirous. Meskipun berbeda dari khat pada umumnya namun tidak merubah kalimat asli dari Al'Quran. Seni lukis Kaligrafi merupakan bentuk kreatifitas baru dalam bidang kesenian Islam yang berkembang seiring dengan tumbuhnya pemikiran tentang nilai estetika dari zaman ke zaman. Hal ini mennerangkan bahwa pada hakikatnya seni kaligrafi itu merupakan suatu rasa kecintaan terhadap yang Ilahiah yang hidup, tumbuh dan berkembang dalam masyarakat.

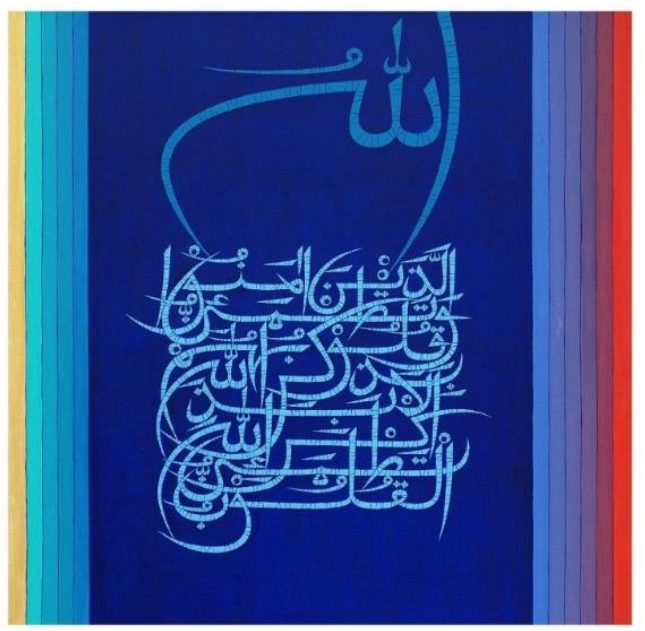

Gambar 1. Lukisan karya Syaiful Adnan

Proses pembuatan kaligrafi hias ini sangat sederhana dengan material-material yang mudah untuk didapatkan. Kayu, triplek, serta kertas-kertas yang tidak terpakai lagi dapat dijadikan sebagai materil pembuatan karya. Pembuatan kaligrafi ini memiliki banyak manfaat diantaranya dapat menerapkan kearifan lokal dalam konten islami, memiliki nilai jual dengan modal yang relative kecil dan dapat dijual dengan harga yang menguntungkan, dapat sebagai sarana edukasi dan bermain positif bagi anak-anak.

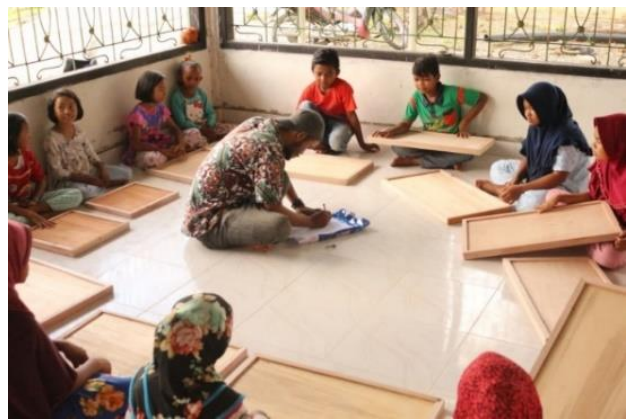

Gambar 2. Proses Awal Penggarapan

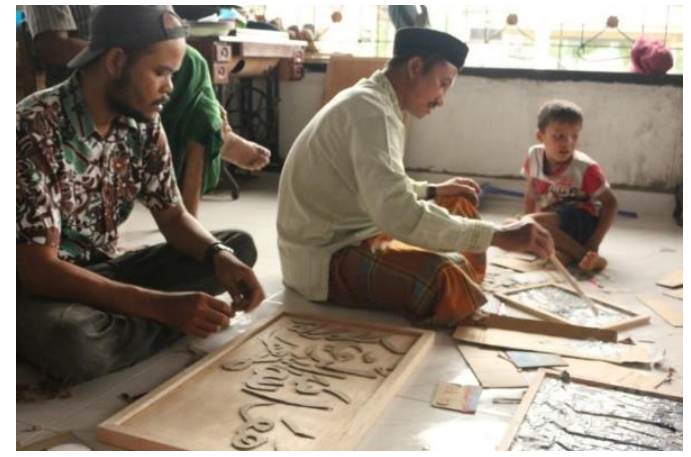

Gambar 3. Tahap Pembentukan

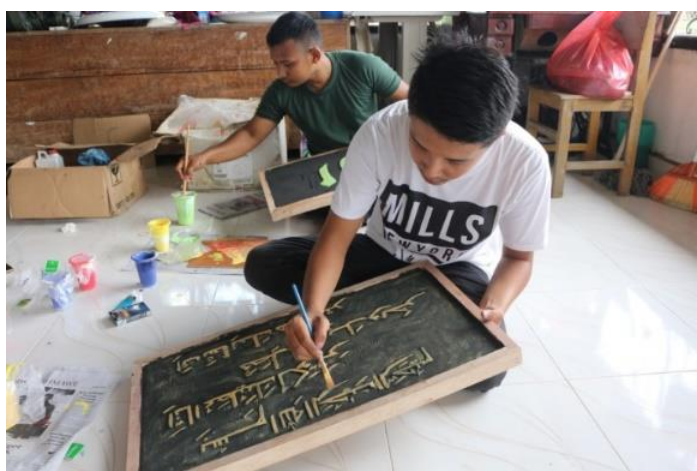

Gambar 4. Tahap Pewarnaan
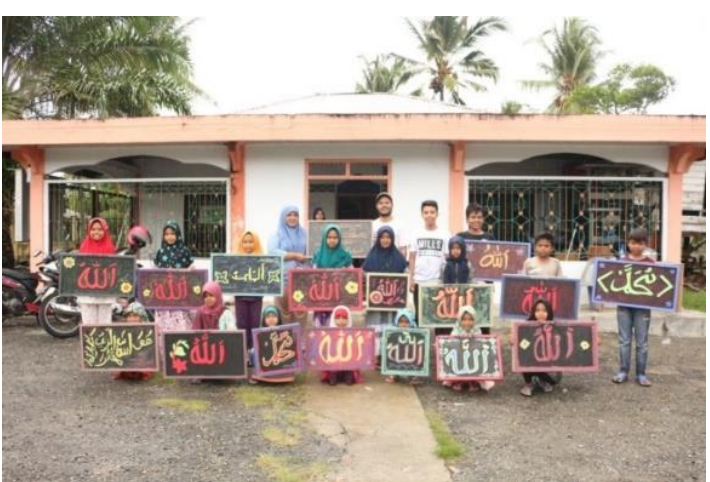

Gambar 5. Kaligrafi Hasil Karya Anak-Anak

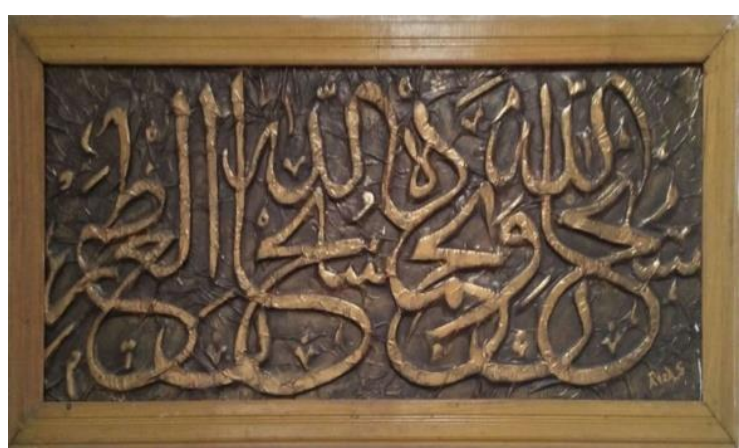

Gambar 6. Hasil Kaligrafi Hias Yang Memiliki Nilai Ekonomis

\section{KESIMPULAN}

Indonesia maerupakan negara yang kaya akan budaya dan keseniannya. Jenis kesenian tiap-tiap daerah memiliki karakter dan ciri khas nya masingmasing. Seperti halnya kebudayaan Aceh yang kental 
akan kebudayaan islami. Budaya islam merupakan landasan hidup masyarakat aceh yang meiliki nilai-nilai luhur yang patut untuk diperjuangkan. Begitu pula dengan seni, yang mana seni harusnya secara menyeluruh di atur oleh hukum islam. Namun di bidang seni rupa di aceh tergolong masih sangat minim. Hal ini sangat disayangkan mengingat aceh memiliki karakteristik budaya yang khas seperti daerah-daerah lainnya. Maka untuk itu diperlukan pembinaan khusus terhadap masyarakat melalui Tri Darma Perguruan Tinggi yang salah satunya adalah pengabdian Masyarakat.

ISBI Aceh sebagai satu-satunya kampus Seni Budaya di pulau sumatera memiliki tanggung jawab yang besar terhadap perkembangan seni budaya khusunya di daerah Aceh Besar. Maka untuk itu pengabdian masyarakat ini berfungsi sebagai wadah untuk kegiatan dosen seni rupa dan desain untuk menerapkan ilmunya di tengah-tengah masyarakat sehingga proses kreatif ini nantinya memberikan dampak positif dan dapat berkesinambungan. Salah satu bentuk upaya pengabdian masyarakat di bidang seni rupa yakni pelatihan "pengolahan kertas bekas menjadi kaligrafi hias" yang nantinya akan menjadi usaha yang memiliki nilai jual .

\section{DAFTAR PUSTAKA}

Ali Masduqi, 2004, Minimisasi Limbah Pada Industri Pulp Dan Kertas Institut Teknologi Sepuluh Nopember

Djelantik, A.A.M. (1999) : Estetika Sebuah Pengantar. Masyarakat Seni Pertunjukan Indonesia

Feldman,E.B,(1967) : Art As Image And Idea, PrinceHall,INC., Englewood Cliff, New Jersey

George Kenneth M. 2012, MELUKIS ISLAM : Amal dan Etika Seni Islam Di Indonesia, Mizan.

M. hatta dahlan, 2011, Pengolahan Limbah Kertas Menjadi Pulp Sebagai Bahan Pengemas Produk Agroindustri, Prosiding Seminar Nasional AVoER ke-3 Palembang

Sri Astuti, 2012, Pemanfaatan Limbah Kertas Koran Sebagai Bahan Utama Pembuatan Tas Dan Sandal Di "Dluwang Art" Sinduadi Sleman Yogyakarta

Tabrani, Primadi, Prof. Dr. 2000, Proses Kreasi, Apresiasi, Belajar, Penerbit ITB, Bandung.

Tabrani, Primadi, Prof. Dr. 2006, Kreativitas dan Humanitas: Sebuah Studi Tentang Peranan Kreativitas dalam Perikehidupan Manusia, Penerbit Jalasutra, Yogyakarta.

Yulia Tesa, 2017, Melakukan Daur Ulang

Kertas Bekas Dan Dimanfaatkan Dalam Kehidupan Sehari- Hari, Jurnal NasionalEcopedon ,payakumbuh 